\title{
In Situ Observation of Lubricant Film in a Diamond Die for Wire Drawing by Micro-FTIR
}

\author{
Yasushi Hoshi ${ }^{1)}$, Hidetaka Nanao ${ }^{1)^{*}}$, Koji Takiwatari ${ }^{2}$, Shigeyuki Mori ${ }^{1)}$ and Takahisa Shizuku ${ }^{3)}$ \\ ${ }^{1)}$ Faculty of Engineering, Iwate University \\ 4-3-5 Ueda, Morioka, Iwate 020-8551, Japan \\ ${ }^{2)}$ National Institute of Technology, Ichinoseki College \\ Takanashi, Hagisho, Ichinoseki, Iwate 021-8511, Japan \\ ${ }^{3)}$ Bridgestone Corporation \\ 3-1-1 Ogawahigashi-cho, Kodaira, Tokyo 187-8531, Japan \\ *Corresponding author: nanao@iwate-u.ac.jp \\ ( Manuscript received 30 October 2015; accepted 20 December 2015; published 30 April 2016) \\ (Presented at the International Tribology Conference Tokyo 2015, 16-20 September, 2015 )
}

\begin{abstract}
The performance of wire drawing is closely dependent on lubrication between die and metal wire. The behavior of lubricants between the die and the wire plays an important role in the lubricating performance for wire drawing. Therefore, the lubricant behavior should be made clearer by a direct observation of the drawing interface in die. The objective of this work is to understand the behavior of lubricants based on the chemical reactions for wire drawing. The drawing properties of these lubricants are discussed on the basis of the generation of metal soap. In situ observation of lubricant film during wire drawing was carried out using a micro-Fourier transform infrared spectroscopy (FTIR). The infrared (IR) spectra of oil film between die and metal wire can be obtained and oil film shape and concentration of additive can be estimated. It was found that oleic acid as an additive reacts with metal wire chemically and metal soap was formed. The concentration of metal soap was distributed to be high at the end of reduction zone under the dynamic conditions.
\end{abstract}

Keywords: wire drawing, brass wire, steel cord, metal soap, micro-FTIR, in situ observation

\section{Introduction}

Wire drawing is a metal working process widely used in industry to reduce wire diameter. For example, a brass-coated steel cord processed like that is used to reinforce the structure of tire. The performance of wire drawing is dependent on lubrication between die and metal wire. The behavior of lubricant between die and wire plays an important role in the lubricating performance for wire drawing. Friction stress at the interface between wire and die affects drawing power and temperature rise at the interface. Wire drawing process employing good lubricants for low friction and good surface finish not only saves energy, but also reduces production costs by avoiding intermediate passes and annealing operations [1]. Lubricating behavior at the interface is dependent on many factors such as drawing speed, material and feature of die, and lubricants. The life of dies is dependent on anti-wear properties of dies and lubrication performance in wire drawing [2]. Drawing process is highly dynamic and the lubricating interface at die cannot be observed directly.
Therefore, most of the studies on wire drawing have been observed ex situ to understand the dynamic process.

In situ observation of lubricant oil film has been carried out during sheet metal forming by a direct fluorescence-observation technique [3]. The oil film thickness was measured by the intensity of fluorescent light from fluorescent dye is dissolved in sample oil. However, this method can measure only oil film thickness. Furthermore, the concentration change of fluorescent dye under the contact condition is not considered. Therefore, the lubricant behavior should be made clearer by a direct and in situ observation of the drawing interface in die.

The authors have been investigating in situ observation of lubricant film under elastohydrodynamic lubrication (EHL) conditions by using micro-FTIR and have reported the oil film thickness [4-6], the concentration of lubricant components [5-6], the pressure of lubricant [7], the molecular orientation [8] and the chemical interaction [9] from IR spectra.

Ex situ observation has been carried out our previous 
(a)

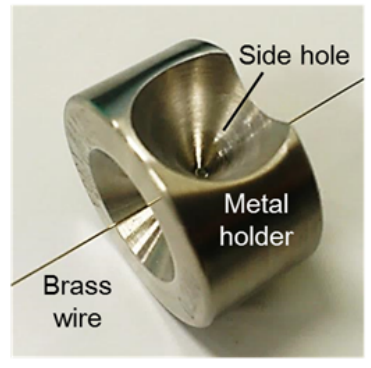

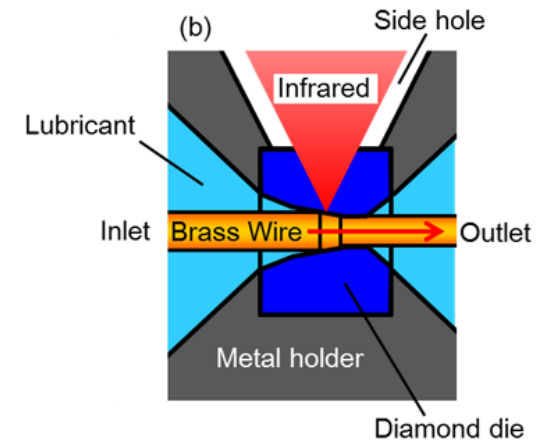

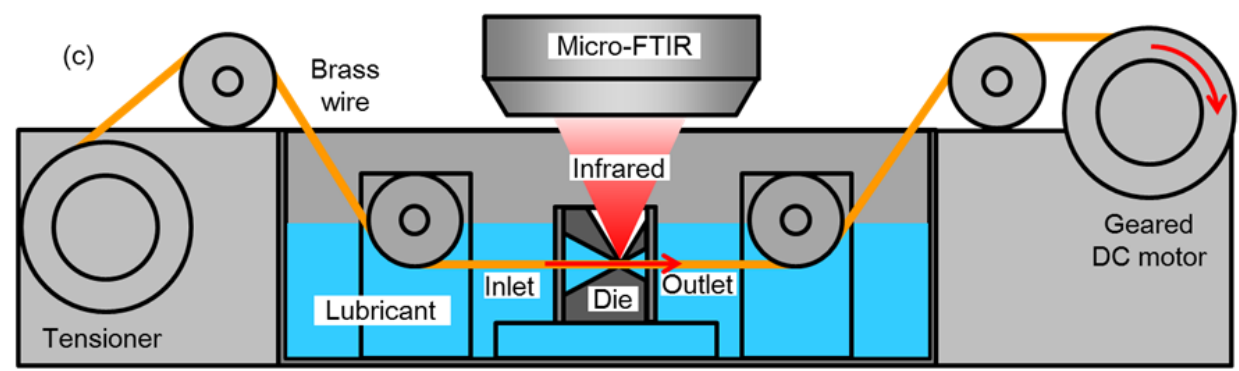

Fig. 1 Photograph (a), schematic cross section (b) of diamond die and overview (c) of wire-drawing apparatus for in situ observation

investigation [10]. In this paper, to apply a new in situ observation method by using micro-FTIR, the lubricant film was observed directly during wire drawing under the dynamic condition. Our in situ observation method can analyze the lubricant film chemically. The objective of this work is to understand the behavior of lubricants based on the chemical reactions for wire drawing. The drawing properties of these lubricants are discussed on the basis of the generation of metal soap formed at interface.

\section{Experimental methods}

\subsection{Sample}

Poly- $\alpha$-olefin (PAO), pure oleic acid (OAc) and 20\% of oleic acid solution in PAO (PAO + OAc) were used as lubricants. A brass (Cu: $65 \%, \mathrm{Zn}: 35 \%)$ wire of 300 $\mu \mathrm{m}$ in diameter was used.

\subsection{Apparatus}

Figure 1 shows a photograph (a) and a schematic cross section (b) of diamond die for the observation with micro-FTIR. A single crystal diamond was used as a die which is held in a metal holder. Diamond is a good transmission material for infrared and visible light. The infrared beam is focused on the metal wire and reflects on the wire surface coming back to IR spectrometer. IR spectra of the lubricant oil film can be obtained by the micro-FTIR spectrometer. Figure 1(c) shows overview of wire drawing apparatus for in situ observation. The wire is wound with a geared DC motor through the die. Furthermore, a drawing force was monitored by an electrical load current of the DC motor. A back-tension was loaded by a tensioner mechanically. The drawing tests are carried out under the condition as follows:

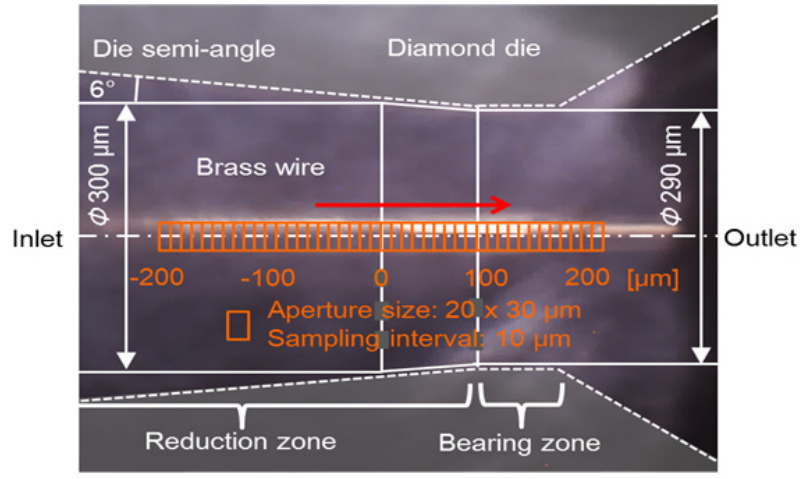

Fig. 2 Optical micrograph of brass wire in the diamond die observed through the side hole

drawing speed $=0.02 \mathrm{~m} / \mathrm{s}$, back-tension $=2 \mathrm{~N}$.

Figure 2 shows the optical micrograph of brass wire in the diamond die observed through the side hole. The inner hole shape of the diamond die is shown by dashed lines which was measured by an optical method. The die semi-angle estimated geometrically is 6 degree. The brass wire is introduced from the left side and is drawn to the right side, and then the wire of $300 \mu \mathrm{m}$ in diameter is drawn to $290 \mu \mathrm{m}$. The aperture size for IR sampling is $20 \mu \mathrm{m} \times 30 \mu \mathrm{m}$ and the sampling position is moved from inlet to outlet at the interval of $10 \mu \mathrm{m}$. The origin of the sampling position is defined at the position where the wire begins to contact with the die.

\section{Results and discussion}

\subsection{Wire drawing properties}

Figure 3 shows the comparison of the drawing force obtained by the electrical load current measurements. The drawing force was reduced with pure OAc and OAc 


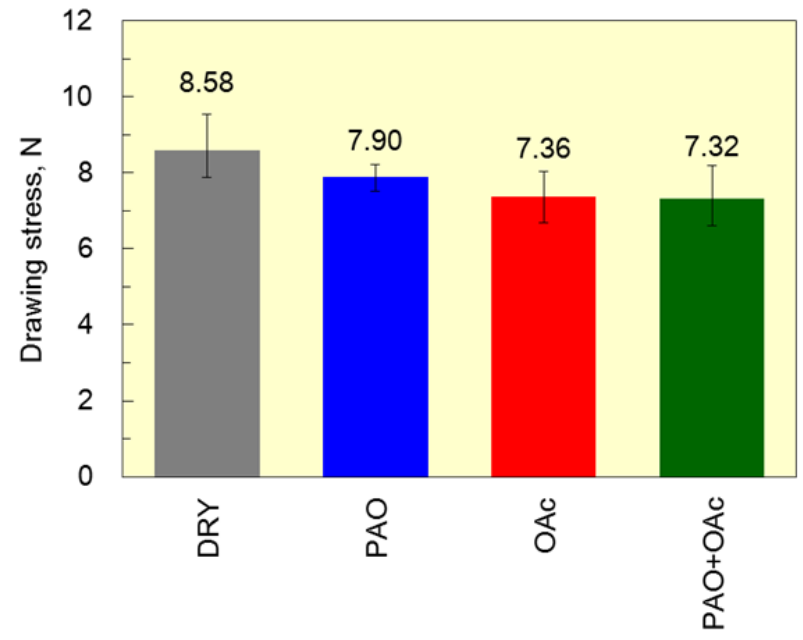

Fig. 3 Comparison of the drawing force by the electrical load current measurement
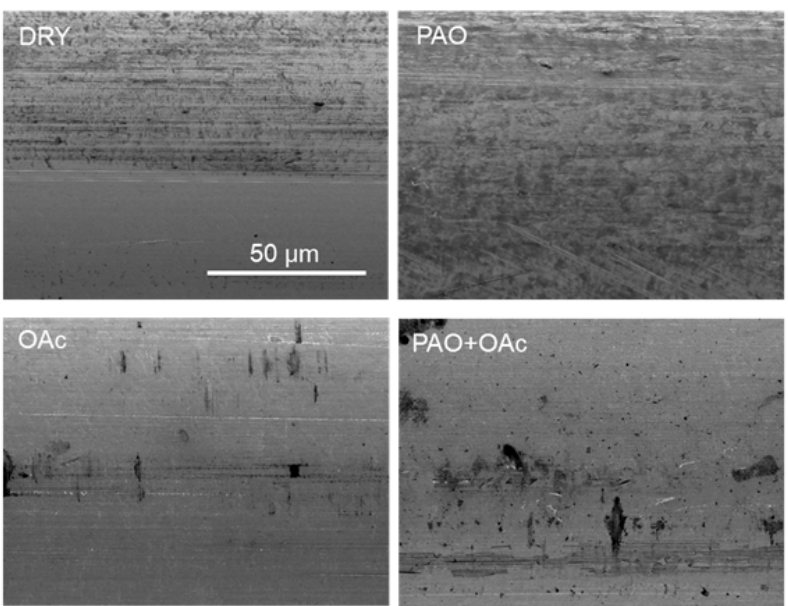

Fig. 4 SEM images of the wire surface after drawing

solution compared with PAO. It is concluded that drawing force can be reduced by an oiliness effect of OAc. Good friction-reducing performance is required in the wire drawing. Since OAc has been used for various lubricants as an oiliness agent, and the oiliness agents are helpful for the lubricating property in the boundary and mixed lubrication. In addition, Fig. 4 shows SEM images of the wire surface after drawing. The wire was drawn in the cross direction in this figure. The mean roughness depth $(R z)$ measured with a laser microscope was $0.20 \mu \mathrm{m}, 0.25 \mu \mathrm{m}, 0.11 \mu \mathrm{m}$ and $0.10 \mu \mathrm{m}$ of the wires drawn with no lubricant, PAO, pure OAc and OAc solution, respectively. Since the surface finish is rough with dry condition and PAO, the adhesive wear was occurred. However, surface finish was very smooth with pure OAc and OAc solution. It is thought that the surface finish improved by OAc. It seems that OAc as an oiliness agent plays an important role for low friction and fine surface finish.

\subsection{IR spectra}

Figure 5 shows IR spectra of the oil film after drawing with PAO, pure OAc and OAc solution. Characteristic peaks can be seen in each spectrum. Two peaks at 3000 and $1400 \mathrm{~cm}^{-1}$ are assigned as the stretching and deformation modes of $\mathrm{CH}$ vibration in PAO, respectively. With pure OAc and OAc solution, there are two additional peaks at 1700 and $1550 \mathrm{~cm}^{-1}$ which are stretching vibrations of $\mathrm{C}=\mathrm{O}$ and $\mathrm{COO}^{-}$of carboxyl group, respectively [11-13]. The peak of $\mathrm{COO}^{-}$ is an evidence for chemical change of OAc to a metal soap. This means that a chemical reaction of OAc with brass is occurred. The natural oxide film of $\mathrm{ZnO}$ on brass surface has been reported to act as a lubricant [14]. These spectra suggest that natural oxide film on brass is reacted with OAc and metal soap is deposited between die and metal wire. Since metal soaps have been used as a lubricant for wire drawing [15], it is thought that the drawing properties were improved by the metal soap. As shown in the spectra, the peak absorbance of $\mathrm{CH}$ stretching vibrations decreases with changing the sampling position from inlet to outlet. This means that the film thickness decreases at the reduction zone, according to the die semi-angle.

The oil film thickness was estimated from the absorbance with a calibration curve which was obtained by IR spectra of a known film thickness. The concentration of metal soap was estimated from the absorbance with these calibration curves. The calibration curves of the absorption coefficient were shown in Fig. 6. Zn oleate was used for estimation of a calibration curve for concentration of metal soap. The reason for using $\mathrm{Zn}$ oleate will be discussed below.

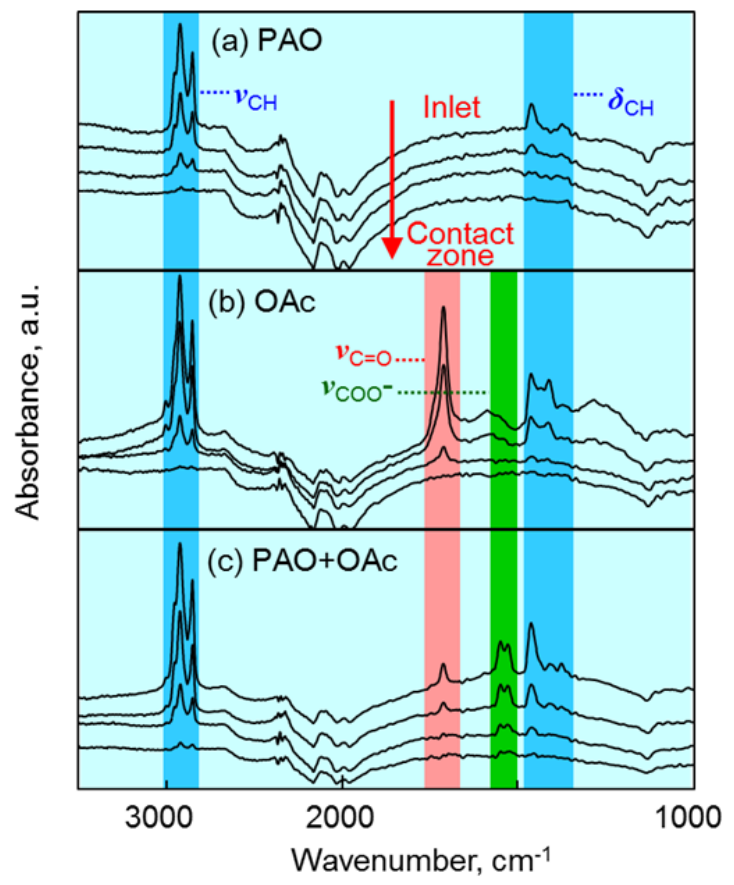

Fig. 5 IR spectra of oil film after drawing with PAO (a), pure OAc (b) and OAc solution (c) 


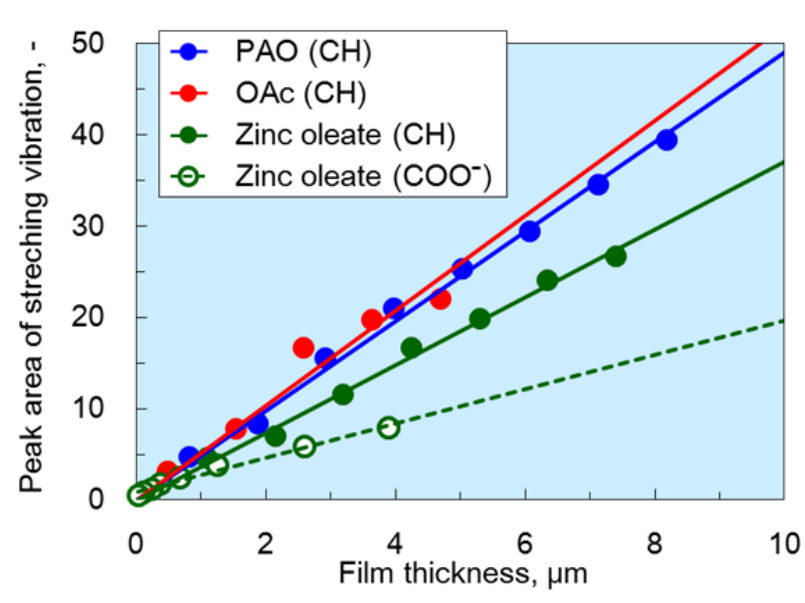

Fig. 6 Calibration curves of the absorption coefficient

\subsection{Static conditions}

Figure 7 shows the profile of the film thickness obtained from the absorbance of $\mathrm{CH}$ stretching vibration after drawing with PAO. A linear relation between the thickness of the space and the absorbance of IR peaks was obtained. The oil film thickness can be estimated indirectly from the absorbance of IR peaks. The broken line is calculated film thickness from the die semi-angle of the reduction zone. No film was observed in the contact zone which is shown by blue painted area, because the thickness is too thin for IR analysis. However, the film thickness increases linearly with increasing distance from the entrance of contact zone. A good linear slope and a good reproducibility of the film thickness were obtained at the reduction zone.

Drawing tests were carried out with lubricants such as pure OAc and OAc solution. Figure 8 shows the profiles of the oil film thickness and the concentration of metal soap after drawing with pure OAc and OAc solution. The film thickness increases linearly with

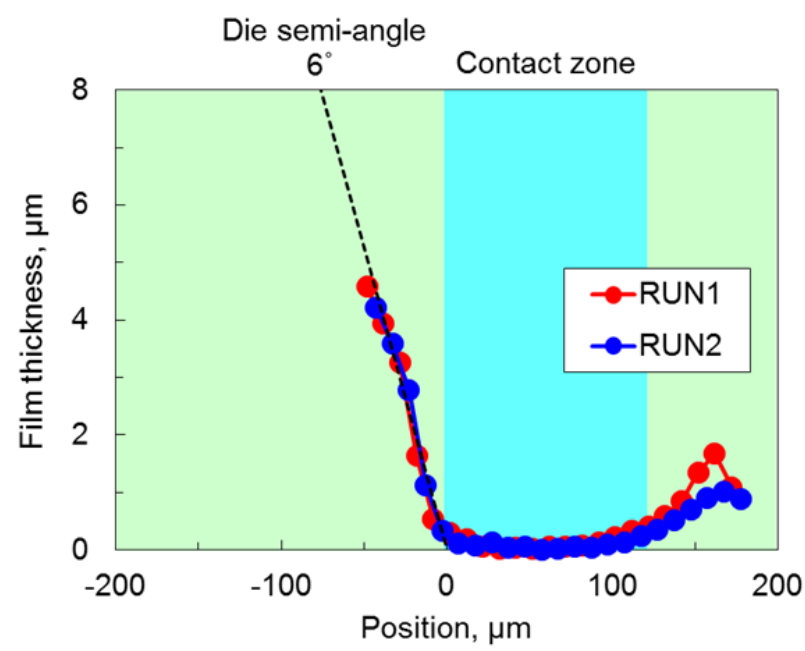

Fig. 7 Profile of the oil film thickness obtained from the absorbance of $\mathrm{CH}$ stretching vibration after drawing with $\mathrm{PAO}$

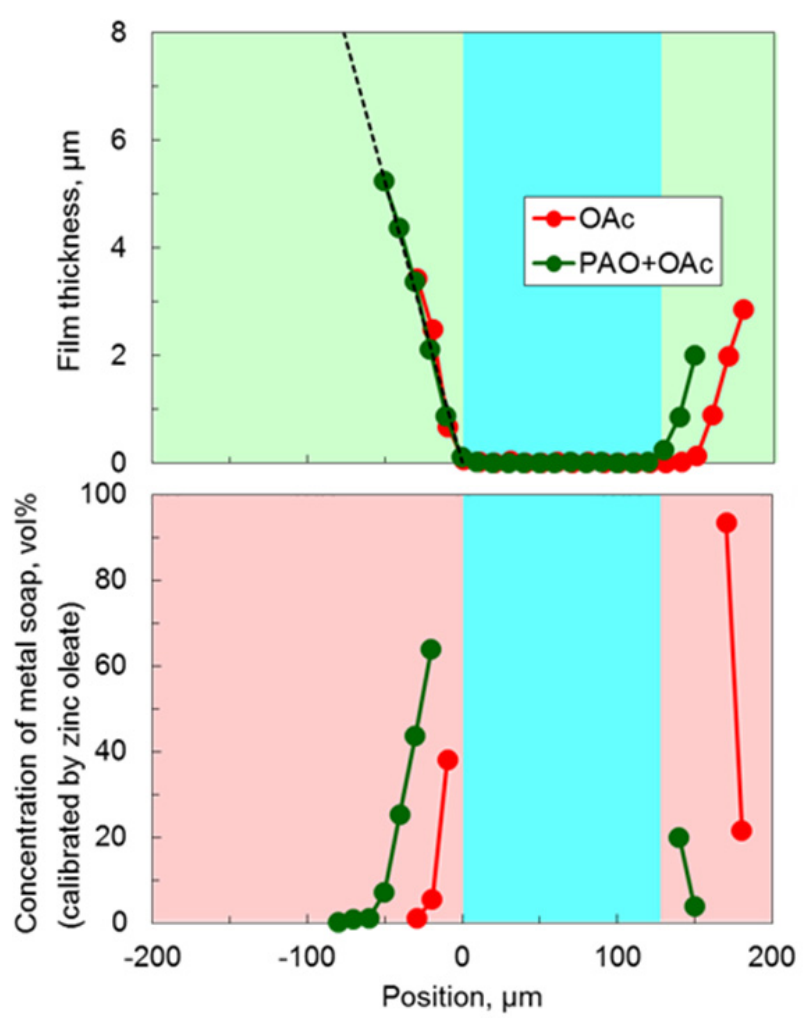

Fig. 8 Profiles of the oil film thickness and the concentration of metal soap after drawing with pure OAc and OAc solution

increasing distance from the end of reduction zone. The concentration of metal soap shows a drastic change at the end of reduction zone. The metal soap was concentrated at the reduction zone. A similar distribution of metal soap was obtained with OAc solution. The concentration at the contact zone is not so exact, because the film is too thin to be estimated.

\subsection{Dynamic conditions}

Figure 9 shows the reproducibility of the film thickness obtained under the dynamic conditions. IR

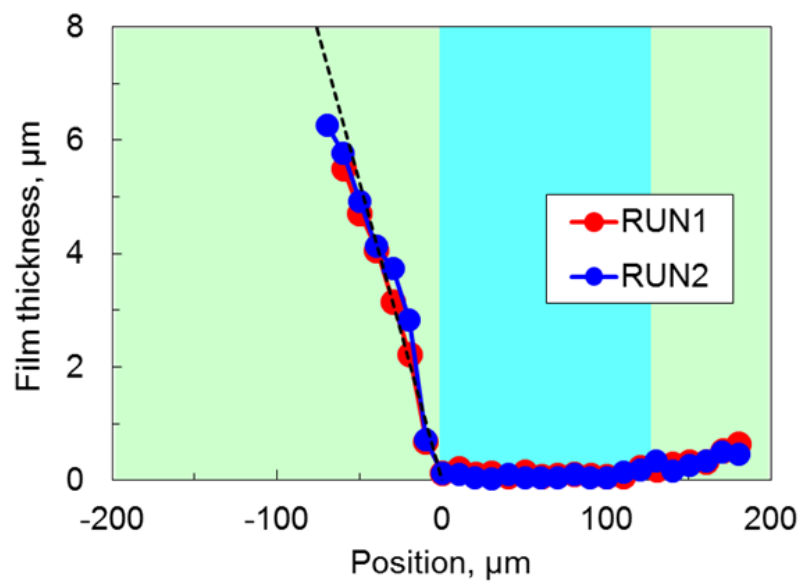

Fig. 9 Reproducibility of oil film thickness obtained during drawing tests with PAO repeated 


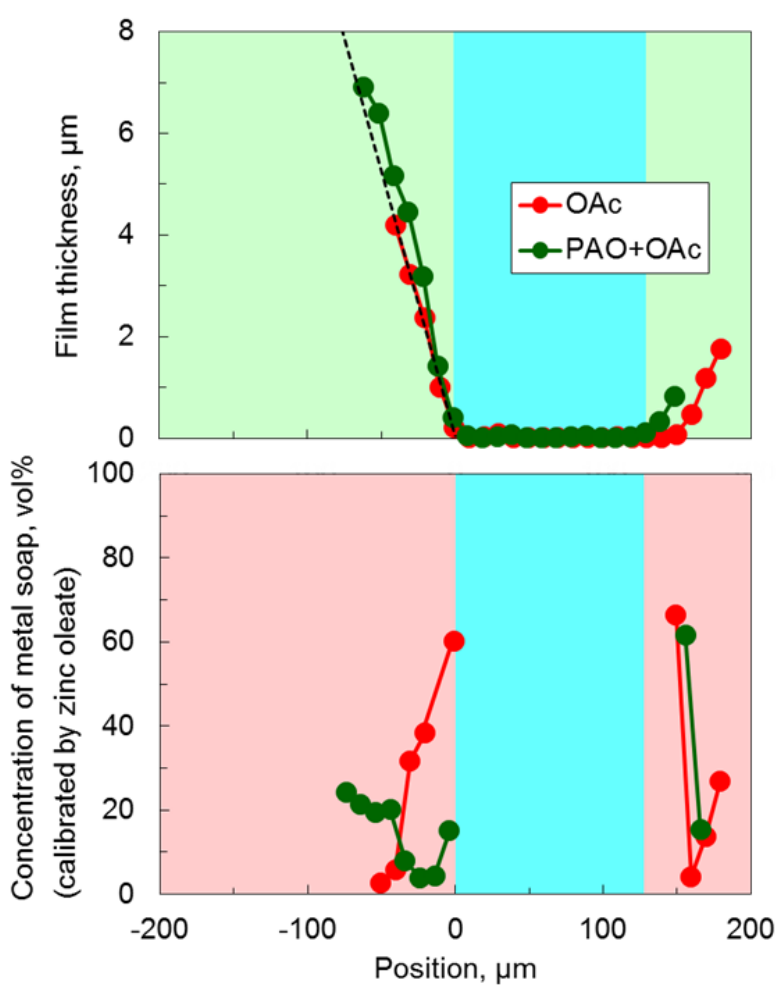

Fig. 10 Profiles of the oil film thickness and the concentration of metal soap during drawing tests with pure OAc and OAc solusion

spectra were obtained during each drawing test with PAO. A good reproducibility of the film thickness was obtained at reduction zone.

In situ observations were carried out with lubricants such as pure OAc and OAc solution. Figure 10 shows the profile of the oil film thickness and the concentration of metal soap obtained during drawing tests with pure OAc and OAc solution. The concentration of metal soap shows a drastic change at the end of reduction zone under the dynamic conditions as well as the static conditions. On the other hand, the generation of metal soap approximately 20 vol $\%$ was observed with OAc solution.

Figure 11 shows the influence of the pretreatment of brass wire on the generation of metal soap with $5 \%$ of

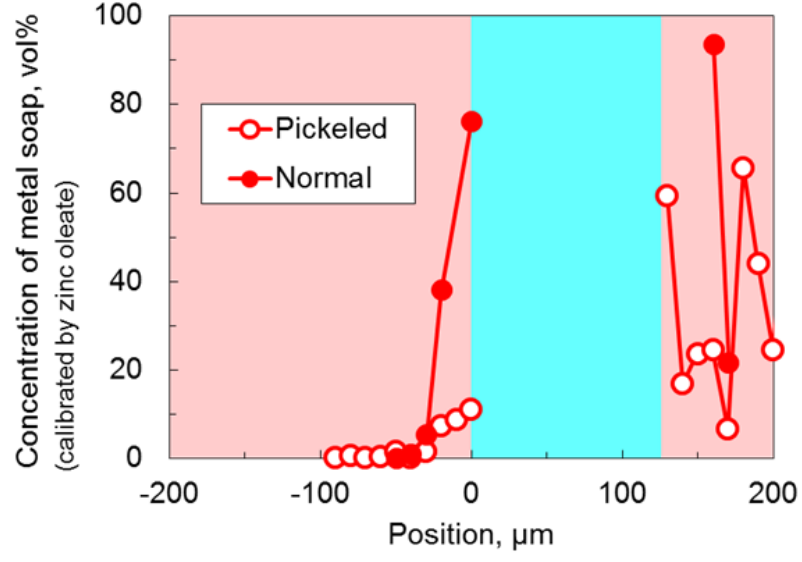

Fig. 11 Influence of the pretreatment of brass wire on the generation of metal soap with $5 \%$ of aqueous $\mathrm{HNO}_{3}$ solution for $30 \mathrm{~s}$

aqueous $\mathrm{HNO}_{3}$ solution for $30 \mathrm{~s}$. When a natural oxide film on brass wire was removed by acid, the generation of metal soap was not observed after drawing with pure OAc. This result is an evidence that natural oxide film participates in the formation of the metal soap.

\subsection{Generation of metal soap}

Figure 12 shows a model of generation and the concentration of metal soap. It was confirmed by a focused ion beam-transmission electron microscope (FIB-TEM) that the surface of the brass wire had the natural oxide film of $20 \mathrm{~nm}$ in thickness. In order to analyze the composition of the natural oxide film of the brass wire, brass wire was dipped in pure OAc at room temperature for 1 hour. The solution was burn out after removal of the brass wire. The residual ash was characterized by a scanning electron microscope-energy dispersive X-ray spectrometry (SEM-EDX), and it was confirmed that the main component of the ash was $\mathrm{Zn}$ oxide. This result indicates that OAc reacts with $\mathrm{Zn}$ oxide on brass wire to produce $\mathrm{Zn}$ oleate at room temperature. This is a neutralizing reaction of amphoteric metal with OAc. The $\mathrm{Zn}$ oleate was concentrated by collecting mechanically at the reduction zone. It has been investigated that a series of metal oleate additives formed a boundary film using ultrathin film interferometry [16].
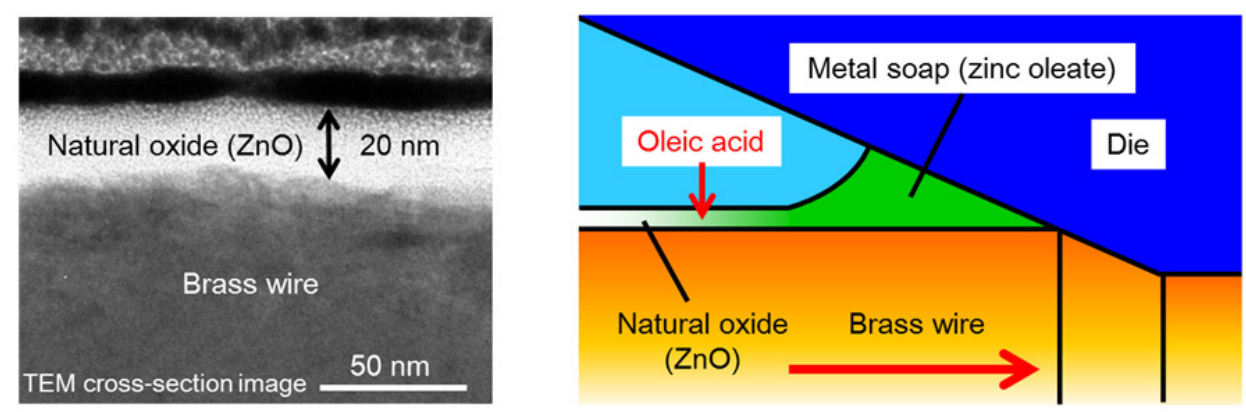

Fig. 12 FIB-TEM of brass wire and model of generation and the concentration of $\mathrm{Zn}$ soap 
Our in situ observation method reported in this paper allows characterizing the lubricant film between die and metal wire. Furthermore, it can provide the information of the chemical components of lubricant film as well as the film thickness by in situ observation. The reaction products of lubricant with natural oxide film can also be characterized by IR spectroscopy.

\section{Conclusions}

In situ observation of lubricant film during wire drawing was carried out using a micro-FTIR. The IR spectra of oil film between die and metal wire can be obtained and the oil film shape and the concentration of additive can be estimated. It was found that OAc as an additive reacts with metal wire chemically and metal soap was formed. The concentration of metal soap was distributed to be high at the end of reduction zone under the dynamic conditions. It was suggested that metal soap had an influence on a drawing force and the surface finish.

In this paper, the neat oils such as PAO and pure OAc and OAc solution were used for lubricants. However, an industrial drawing for a steel tire cord was used an oil-in-water $(\mathrm{O} / \mathrm{W})$ emulsion as a lubricant. In situ observation of $\mathrm{O} / \mathrm{W}$ emulsion will be investigated in the next research.

\section{Acknowledgments}

A part of this work was supported by "Green Tribology Innovation Network", Advanced Environmental Materials Area, GRENE program sponsored by MEXT of Japan.

\section{References}

[1] Weber, R. D., "Energy Saving in Drawing Operations," J. Wire Ind., 61, 1994, 255-258.

[2] Hollinger, S., Depractere, E. and Giroux, O., "Wear Mechanism of Tungsten Carbide Dies During Wet Drawing of Steel Tyre Cords," Wear, 255, 7-12, 2003, 1291-1299.

[3] Azushima, A., "In Lubro 3D Measurement of Oil Film Thickness at the Interface Between Tool and Workpiece in Sheet Drawing Using a Fluorescence Microscope," Tribol. Intern., 38, 2, 2005, 105-112.

[4] Takiwatari, K., Nanao, H. and Mori, S., "Effect of High Pressure on Molecular Interaction Between Oleic Acid and Base Oils at Elastohydrodynamic Lubrication Contact," Lubr. Sci., 22, 3, 2010, 89-101.
[5] Hoshi, Y., Shimotomai, N., Sato, M. and Mori, S., "Change of Concentration of Additives Under EHL Condition,” J. Jpn. Soc. Tribol., 44, 9, 1999, 736-743 (in Japanese).

[6] Shimotomai, N. and Mori, S., "In-Situ Observation of the Lubrication Film in O/W Emulsion by Micro FT-IR,” J. Jpn. Soc. Tribol., 56, 1, 2011, 47-54 (in Japanese).

[7] Takiwatari, K., Nanao, H., Suzuki, E. and Mori, S., "Stabilisation of Hydrogen Bonding in Polypropylene Glycol at EHL Contact region," Lubr. Sci., 22, 9, 2010, 367-376.

[8] Mori, S. and Iwata, H., "Relationship Between Tribological Performance of Liquid Crystals and Their Molecular Structure," Tribol. Intern., 29, 1, 1996, 35-39.

[9] Takiwatari, K., Nanao, H. and Mori, S., "Effect of Pressure and Temperature on the Molecular Interaction of Polar Lubricant Containing Oleic Acid in Polypropylene Glycol Observed by Infrared Spectroscopy," Lubr. Sci., 26, 1, 2014, 13-22.

[10] Nanao, H., Hoshi, Y., Shizuku, T., Takiwatari, K. and Mori, S., "Direct Observation of Lubricant Components Between Wire and Diamond Die for Wire Drawing with a Micro-FTIR," Tribol. Lett., 60, 12, 2015, DOI:10.1007/s11249-015-0592-4.

[11] Roberts, K. and Friberg, St., "Phase Transitions of Adsorbed Carboxylic Acids on Zinc Oxide and of Zinc Soaps. Infrared and X-Ray Diffraction Investigations," Colloid Polym. Sci., 230, 2, 1969, 357-362.

[12] Cann, P. M. and Spikes, H. A., "In-Contact IR Spectroscopy of Hydrocarbon Lubricants," Tribol. Lett., 19, 4, 2005, 289-297.

[13] Cann, P. M.,"Grease Degradation in a Bearing Simulation Device," Tribol. Inter., 39, 12, 2006, 1698-1706.

[14] Feser, T., Stoyanov, P., Mohr, F. and Dienwiebel, M., "The Running-In Mechanisms of Binary Brass Studied by In Situ Topography Measurements," Wear, 303, 1-2, 2013, 465-472.

[15] Felder, E., Levrau, C., Mantel, M. and Dinh, N. G. T., "Identification of the Work of Plastic Deformation and the Friction Shear Stress in Wire Drawing," Wear, 286-287, 2012, 27-34.

[16] Ratoi, M., Bovington, C. and Spikes, H., "In Situ Study of Metal Oleate Friction Modifier Additives," Tribol. Lett., 14, 1, 2003, 33-40. 